\title{
Mate Retention Inventory-Short Form (MRI-SF): Adaptation to the Brazilian context
}

\author{
Guilherme S. Lopes ${ }^{\text {a,* }}$, Todd K. Shackelford ${ }^{\text {a }}$, Walberto S. Santos ${ }^{\text {b }}$, Mariana G. Farias ${ }^{\text {b }}$, Damião S.A. Segundo ${ }^{\text {b }}$ \\ a Oakland University, Rochester, MI 48309, United States \\ b Universidade Federal do Ceará, Fortaleza, CE 60020-181, Brazil
}

\section{A R T I C L E I N F O}

\section{Article history:}

Received 29 August 2015

Received in revised form 15 October 2015

Accepted 16 October 2015

Available online 26 October 2015

\section{Keywords:}

Mate retention

Validity

Reliability

Sex differences

Evolutionary psychology

\begin{abstract}
A B S T R A C T
This study secured evidence of the validity and reliability of the Mate Retention Inventory-Short Form (MRI-SF) in the Brazilian context. Participants were 212 individuals in a long-term, heterosexual, romantic relationship residing in Fortaleza, aged between 18 and 59 years $(M=26.3, S D=7.5)$, mainly female $(58.5 \%)$ and attending college (60.8\%). The average duration of the romantic relationship was 59.3 months (SD $=63.8$ months). Participants answered demographic questions and completed a Brazilian Portuguese translation of the MRI-SF, which presents 38 items that assess how often participants performed each mate retention act described. The results indicated a two-factor structure that explained $33.3 \%$ of the total variance. The results also indicated that men and women differentially use several mate retention tactics. These results are discussed in light of evolutionary hypotheses of mate selection, and we highlight limitations of the current research and identify important directions for future research.
\end{abstract}

(c) 2015 Elsevier Ltd. All rights reserved.

\section{Introduction}

Long-term romantic partnership between a man and a woman is the most common human mating arrangement (Buss, 2003). In fact, longterm mating conferred benefits for both sexes over the deep time of our evolutionary past. For men, these benefits included an increase in paternity certainty, and for women, these benefits included reliable partner investment in the woman and her children (Gallup \& Frederick, 2010). Although these are not the only benefits that long-term mating brings to men and women, continued receipt of these and other benefits selected for psychological mechanisms in both men and women that motivate efforts to retain a long-term mate (Buss, Shackelford, \& McKibbin, 2008).

Therefore, mate retention efforts differ from (and occur after) the efforts to acquire a long-term partner (Buss, 2003), and efforts allocated to retaining a long-term partner repay reproductively the effort allocated to mate acquisition (Buss et al., 2008). Buss (1988) presented the first attempt to identify and assess mate retention behavior in humans. He developed the Mate Retention Inventory (MRI), which assesses the performance of 19 mate retention tactics with responses to 104 specific behaviors. The tactics are organized into five factors, subdivided into two domains: intrasexual manipulations (i.e. tactics directed toward

\footnotetext{
* Corresponding author at: Oakland University, Department of Psychology, 107 Pryale Hall, Rochester, Michigan 48309, United States.

E-mail addresses: gslopes@oakland.edu (G.S. Lopes), shackelf@oakland.edu (T.K. Shackelford), walbertosantos@gmail.com (W.S. Santos), mariana_gfarias@hotmail.com (M.G. Farias),damiao_soares@hotmail.com (D.S.A. Segundo).
}

one's partner) and intersexual manipulations (i.e. tactics directed toward same-sex competitors).

The intersexual manipulations domain includes three factors:

1) Direct guarding (comprised of the following tactics: vigilance, e.g. "He read her personal mail"; concealment of mate, e.g. "He did not let her talk to the other males"; and monopolize mate's time, e.g. "He would not let her go out without him");

2) Intersexual negative inducements (threaten infidelity, e.g. "He flirted with another woman in front of her"; punish mate's threat to infidelity, e.g. "He became angry when she flirted too much"; emotional manipulation, e.g. "He cried in order to keep her with him"; commitment manipulation, e.g. "He asked her to marry him"; and derogation of competitors, e.g. "He pointed out to her the other guy's flaws");

3) Positive inducements (resource display, e.g. "He bought her an expensive gift"; sexual inducements, e.g. "He performed sexual favors to keep her around"; enhancing physical appearance, e.g. "He made sure that he looked nice for her", emphasize love and caring, e.g. "He told her that he loved her"; and submission and debasement, e.g. "He acted against his will to let her have her way").

The intrasexual manipulations domain includes two factors:

4) Public signals of possession (verbal signals of possession, e.g. "He told his male friends how much they were in love"; physical signals of possession, e.g. "He kissed her when the other guys were around"; and possessive ornamentation, e.g. "He gave her jewelry to signify that she was taken");

5) Intrasexual negative inducements (derogation of mate to competitors, e.g. "He told other guys that she was stupid"; intrasexual 
threats, e.g. "He told the other guy to stay away from her"; and Violence, e.g. "He hit the guy who made a pass at her").

Empirical research provides evidence for the reliability, validity, and utility of the MRI in North America (e.g. Pham \& Shackelford, 2013; Shackelford, Goetz \& Buss, 2005), Spain (de Miguel \& Buss, 2011) and Croatia (Kardum, Hudek-Knezevic, \& Gracanin, 2006). Furthermore, Miner, Starratt, and Shackelford (2009) suggested a superordinate structure for the MRI that includes five categories subdivided into two domains. Cost-inflicting mate retention behaviors (direct guarding, Intersexual negative inducements and intrasexual negative inducements) reduce the likelihood of partner infidelity by inflicting or threatening to inflict costs on the partner for infidelity or defection. Benefitprovisioning mate retention behaviors (positive inducements and Public signals of possession) reduce the likelihood of partner infidelity by bestowing benefits on the partner, to thereby increase the attractiveness of the relationship.

Because the 104-item MRI is time-consuming to complete, Buss et al. (2008) developed the Mate Retention Inventory Short Form (MRI-SF). The MRI-SF assesses the 19 tactics by securing responses to the two items from the longer form that load highest on each tactic, for a total of 38 items. All two-item tactics showed acceptable internal consistency and correlated with their respective tactic in the original form, suggesting that the two-item scales provide reasonable assessments of each of the 19 tactics (Buss et al., 2008).

Previous research has identified evolutionarily-predicted sex differences in the use of several mate retention tactics (Buss, 1988; Buss \& Shackelford, 1997; Kardum et al., 2006; Pham, Barbaro, Mogilski, \& Shackelford, 2015). For example, men more than women use resource display, and women more than men use appearance enhancement (Buss, 1988; Buss \& Shackelford, 1997; de Miguel \& Buss, 2011). These sex differences were predicted by an evolutionary perspective on mate selection (Buss, 2003). According to this perspective, men perceive as more attractive women who display cues to greater reproductive capacity (Geldart, 2010). Because these cues are related to physical characteristics, women more than men are predicted to use appearance enhancement as a mate retention tactic. In contrast, women more than men prefer as longterm partners individuals that display current or future resource acquisition (Buss, 2003). Men more than women, therefore, are predicted to use resource display as a mate retention tactic.

No previous research has investigated mate retention in Brazil. We searched Google Scholar (2015), PsycINFO (2015) and PubPsych (2015) using the keyword "mate retention", and we found no publications using Brazilian samples. We then used the keyword retenção de parceiros ("mate retention" in Brazilian Portuguese), and this search returned 20 publications, but none of them empirical. Mate retention research conducted in Brazil may have theoretical value. Investigating cross-cultural differences is central to accumulating evidence that might strengthen evolutionary hypotheses, and evolutionarilypredicted sex differences in the use of mate retention tactics have been investigated in Spain (de Miguel \& Buss, 2011) and Croatia (Kardum et al., 2006). Mate retention research may also have applied value. For instance, men's use of specific mate retention tactics, such as vigilance and monopolization of time, is correlated with men's physical violence against their partners (Shackelford, Goetz, Buss, Euler \& Hoier, 2005), suggesting that the use of these tactics may portend domestic violence. The results of mate retention research may be useful in practical contexts such as in developing educational programs, marital counseling, and marital therapy (Buss et al., 2008).

The goal of the current research was to investigate mate retention in Brazil, by first adapting and validating the MRI-SF to the Brazilian context, which we refer to as the Escala de Retenção de Parceiros Reduzida (ERP-R). Additionally, as part of the evaluation of the construct validity of the ERP-R, we investigated sex differences in use of mate retention tactics.

\section{Method}

\subsection{Participants}

The original dataset included responses from 259 individuals. However, in parallel with previous research on mate retention (e.g., Buss et al., 2008), we analyzed only responses provided by individuals in a heterosexual, romantic relationship for at least six months in the last year. The final sample included 212 individuals residing in Fortaleza, aged between 18 and 59 years $(M=26.3$; $S D=7.5,90.9 \%$ younger than 35 years), mostly female (58.5\%) and attending college (60.8\%). The mean relationship length was 59.3 months $(S D=63.8)$. This sample size is above the minimum suggested for principal component analyses (Kline, 1979).

\subsection{Materials}

Participants answered a booklet composed by two parts:

Escala de Retenção de Parceiros Reduzida (ERP-R, see supplemental material). This is a Brazilian Portuguese version of the MRI-SF (Buss et al., 2008), and includes 38 items, two each assessing 19 tactics. The tactics index five components and two domains (see Introduction). Participants indicate the frequency with which they performed each act in the past six months on a 4 -point Likert scale $(0=$ Never and $3=$ Often $)$. The tactics of the MRI-SF showed reasonable internal consistencies given the inclusion of only two items per tactic (Cronbach's alpha varying from .40 to .87), and scores on the tactics correlate positively across the MRI (Buss, 1988) and MRI-SF (Pearson's $r$ varying from .81 to .99).

Demographic questions. We included demographic questions (e.g., age, gender), as well as questions about the romantic relationship. Specifically, we asked the following Yes/No questions: 1) "Are you in a romantic relationship?", 2) "Have you been in this relationship for at least 6 months?", 3) "Did you commit infidelity at least once in your lifetime?", and 4) "Were you betrayed at least once in your lifetime?". We also asked questions to which participants responded on a 5-point Likert scale with $1=$ Low and $5=$ High: 5 ) "What are the odds that your relationship will exist in 12 months?", 6) "To what extent are you satisfied with your relationship?", 7) "What is the physical intimacy level of your relationship?", and 8) "What is the emotional intimacy level of your relationship?". Finally, participants were asked to indicate the length of the relationship ["What is the approximate duration of the relationship (in months)?"].

\subsection{Procedure}

\subsubsection{Translation of the MRI-SF}

The translation followed the guidelines suggested by Borsa, Damásio, and Bandeira (2012). Specifically: 1) two bilingual translators translated the MRI-SF from English to Brazilian Portuguese, resulting in two translated versions; 2) two bilingual translators synthetized the versions by comparing them and evaluating semantic, idiomatic, conceptual, linguistic and contextual discrepancies, resulting in a single Brazilian Portuguese version; 3) one bilingual translator compared this version and the English version, suggesting semantic adjustments; 4) we administered the translated version to five residents of Fortaleza to identify abstruse terms, which were replaced with synonyms (semantic validation); 5) two bilingual translators performed the back translation; and 6) an author of the original version (Buss et al., 2008) compared the original and the back-translated versions, indicating minor modifications to improve the equity of the translated version.

\subsubsection{Data collection}

We collected data from public places and approached prospective participants at random. We explained that participation was anonymous to limit responses motivated by social desirability concerns. Only individuals at least 18 years old who provided informed consent 
were allowed to participate. Most participants completed the survey in $10 \mathrm{~min}$.

\subsubsection{Data analysis}

Following Buss (1988) and recent studies (Miner, Starratt, et al., 2009; Pham \& Shackelford, 2013), we constructed 19 tactics from the mean scores of the two items of each tactic. We performed Multivariate Analysis of Variance (MANOVA) to assess the discriminative power of the tactics, and Multivariate Analysis of Covariance (MANCOVA) to investigate sex differences in use of mate retention tactics, controlling for age and relationship length. We performed Principal Component Analysis (PCA) to evaluate structure of the 19 tactics, and calculated Cronbach's alpha for the internal consistencies of the 19 tactics.

\section{Results}

Most of the tactics showed acceptable internal consistency reliability, similar to those reported by Buss et al. (2008). Table 1 summarizes which items are included in each tactic, as well as tactic-level internal consistencies identified in this study, in the research conducted to develop the MRI-SF (Buss et al., 2008), and in the research conducted to develop the original MRI (Buss, 1988) for comparison.

We next evaluated the discriminative power of the items, considering the median total score as the dividing point. We calculated the total score across the 19 tactics for each participant, then divided these scores into two criterion groups, i.e. those above and those below the median $(\mathrm{Mdn}=1.17)$. We entered the items into a MANOVA to evaluate differences in mean scores of the 19 items (dependent variables) between the criterion groups. Results indicated that the null hypothesis of no difference in mean scores of the items for the criterion groups was rejected [Wilks' Lambda $=.65, \mathrm{~F}(19,188)=5.38, p<.001, p^{2}=.35$ ]. However, MANOVA does not indicate for which items the observed means differ. We therefore performed univariate tests (of between-subjects effects). All items separately showed mean differences between the criterion groups ( $p s \leq .05$ ), suggesting that all items discriminate individuals who scored high from those who scored low.

Kaiser-Meyer-Olkin (.77) and Bartlett's sphericity tests $\left[\chi^{2}(171)=\right.$ $860.45, p \leq .001$ ] supported the suitability of the data for PCA. The former indicates the total amount of variance that might be caused by a common factor, with .50 suggested as the minimum acceptable value (Kaiser, 1970), whereas the latter indicates the existence of correlations

Table 1

Internal consistency of mate retention tactics $(\mathrm{n}=212)$.

\begin{tabular}{lllll}
\hline \multirow{2}{*}{ Tactics } & Items & \multicolumn{3}{l}{ Internal consistency $(\alpha)$} \\
\cline { 3 - 5 } & & ERP-R & MRI-SF $^{1}$ & MRI $^{2}$ \\
\hline Vigilance & $01 / 20$ & .57 & .63 & .81 \\
Concealment of mate & $02 / 21$ & .26 & .40 & .64 \\
Monopolization of time & $03 / 22$ & .48 & .53 & .70 \\
Jealousy induction & $04 / 23$ & .58 & .70 & .72 \\
Punish mate's infidelity threat & $05 / 24$ & .50 & .57 & .79 \\
Emotional manipulation & $06 / 25$ & .63 & .61 & .78 \\
Commitment manipulation & $07 / 26$ & .17 & .42 & .41 \\
Derogation of competitors & $08 / 27$ & .57 & .68 & .75 \\
Resource display & $09 / 28$ & .35 & .65 & .83 \\
Sexual inducements & $10 / 29$ & .46 & .40 & .64 \\
Appearance enhancement & $11 / 30$ & .65 & .74 & .81 \\
Love and care & $12 / 31$ & .45 & .55 & .65 \\
Submission and debasement & $13 / 32$ & .63 & .61 & .73 \\
Verbal possession signals & $14 / 33$ & .55 & .66 & .62 \\
Physical possession signals & $15 / 34$ & .54 & .65 & .74 \\
Possessive ornamentation & $16 / 35$ & .68 & .66 & .58 \\
Derogation of mate & $17 / 36$ & .44 & .49 & .66 \\
Intrasexual threats & $18 / 37$ & .75 & .87 & .82 \\
Violence against rivals & $19 / 38$ & .44 & .67 & .79 \\
Total & & .83 & .90 & - \\
\hline
\end{tabular}

Note. ${ }^{1}$ Buss et al., 2008; ${ }^{2}$ Buss, 1988. in the data set by testing the null hypothesis that all variables are uncorrelated. We proceeded with a PCA without setting the number of components to be extracted. We found six components meeting the Kaiser criterion (eigenvalue $\geq 1$ ), explaining $58.7 \%$ of total variance. However, the scree plot (Cattell criterion, see Fig. 1) suggested two components, a suggestion corroborated by the results of a parallel analysis (Horn criterion). The parallel analysis generates randomized data with the same parameters of the observed data (i.e., 212 participants and 19 variables).The Horn criterion suggests retention of components for which the eigenvalue in the observed data is greater than the associated eigenvalue in the randomized data (Horn, 1965).

Component extraction criteria suggested different numbers of components for extraction, but since the Horn criterion is the most rigorous (Garrido, Abad, \& Ponsoda, 2013) and since two of three criteria (Cattell and Horn) suggested a two-component structure, we performed another PCA, setting the number of components to two and following with varimax rotation. Components 1 and 2 produced eigenvalues of 4.11 and 2.22, respectively, and explained $33.3 \%$ of the total variance. For Component 1, the tactics had loadings from .35 to .69. Component 2 had tactics with loadings from .34 to .74. Cronbach's alpha for Components 1 and 2 were .74 and .75, respectively. These results are summarized in Table 2 .

As part of the evaluation of the construct validity of the ERP-R, we performed a MANCOVA to investigate sex differences in use of mate retention tactics, controlling for age and relationship length. The results indicated that men and women differentially use the mate retention tactics [Wilks' Lambda $=.59, \mathrm{~F}(19,148)=5.31, p \leq .001, p^{2}=.40$ ], even after controlling for age and relationship length. Tests of between-subjects effects indicated which tactics generated sex differences (see Table 3).

Finally, we performed a MANCOVA to identify sex differences in the scores on Components 1 and 2, controlling for age and relationship length. Although the results indicated sex differences on the components [Wilks' Lambda $=.89, \mathrm{~F}(2,167)=10.13, p \leq .001, p^{2}=.11$ ], tests of between-subjects effects indicated a significant difference only for Component $2\left(\beta=.22 ; \mathrm{F}(1,168)=13.52, p<.001 ; p^{2}=.07\right)$.

\section{Discussion}

We aimed to develop and psychometrically validate a Brazilian Portuguese-language adaptation of the MRI-SF (Buss et al., 2008) for use in Brazil, which we term the Escala de Retenção de Parceiros Reduzida (ERP-R). The results are generally in line with expectations. Similar to Buss (1988), Cronbach's alpha for each tactic were mostly below the minimum suggested as acceptable (.70, Nunnally, 1970).

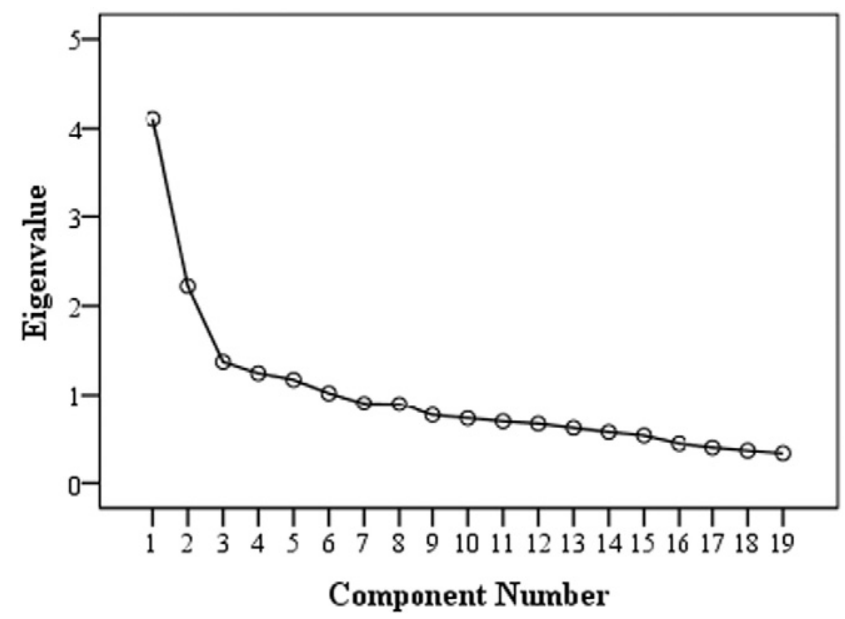

Fig. 1. Scree plot of the tactics of the ERP-R. 
Table 2

Component structure and loadings of the mate retention tactics $(\mathrm{n}=212)$.

\begin{tabular}{|c|c|c|c|}
\hline \multirow[t]{2}{*}{ Tactics } & \multicolumn{2}{|c|}{ Factor loadings } & \multirow[t]{2}{*}{$h^{2}$} \\
\hline & Factor I & Factor II & \\
\hline Emotional manipulation & .65 & .12 & .44 \\
\hline Commitment manipulation & .54 & .08 & .30 \\
\hline Derogation of competitors & .35 & .18 & .16 \\
\hline Resource display & .43 & .00 & .18 \\
\hline Sexual inducements & .51 & .25 & .33 \\
\hline Appearance enhancement & .44 & .05 & .20 \\
\hline Love and care & .59 & -.17 & .38 \\
\hline Submission and debasement & .55 & -.02 & .31 \\
\hline Verbal possession signals & .70 & .09 & .49 \\
\hline Physical possession signals & .41 & .04 & .17 \\
\hline Possessive ornamentation & .47 & .18 & .26 \\
\hline Vigilance & .11 & .72 & .54 \\
\hline Concealment of mate & .15 & .34 & .14 \\
\hline Monopolization of time & .33 & .55 & .41 \\
\hline Jealousy induction & -.04 & .73 & .53 \\
\hline Punish mate's infidelity threat & .13 & .74 & .57 \\
\hline Derogation of mate & -.08 & .51 & .27 \\
\hline Intrasexual threats & .36 & .60 & .49 \\
\hline Violence against rivals & -.04 & .40 & .16 \\
\hline Eigenvalue & 4.11 & 2.22 & \\
\hline Explained variance (\%) & 21.63 & 11.68 & \\
\hline Internal consistency (Cronbach's alpha) & .74 & .75 & \\
\hline
\end{tabular}

The bolded numbers refer to the factor loading of each tactic in its respective factor.

However, each tactic is comprised of two items only, and the number of items interferes in Cronbach's alpha value. Internal consistency indexes less than .70 are expected for scales with very few items (a high alpha value with very few items indicates item redundancy). Cronbach's alpha seems to be a good reliability index for two-item scales (Eisinga, TeGrotenhuis, \& Pelzer, 2013).

The tactics generated internal consistencies similar to Buss et al. (2008), except for Commitment manipulation, which showed a lower Cronbach's alpha (relative to the other tactics). This lower alpha is likely attributable to the low variance of item 26, "Asked my partner to marry me" (70\% scored "0"). The sample was comprised of individuals in a romantic relationship of several types, from dating for six months to married. Among individuals who are married, those who were asked to marry scored " 0 " (never, since they were already married), and those who asked their partner to marry them scored "1" (rarely), as they

Table 3

Tests of between-subjects effects regarding gender and mate retention tactics $(n=170)$.

\begin{tabular}{|c|c|c|c|c|c|c|}
\hline \multirow[t]{2}{*}{ Tactics } & \multicolumn{2}{|c|}{$\begin{array}{l}\text { Men } \\
(\mathrm{n}=71)\end{array}$} & \multicolumn{2}{|c|}{$\begin{array}{l}\text { Women } \\
(\mathrm{n}=99)\end{array}$} & \multirow[t]{2}{*}{$p^{2}$} & \multirow[t]{2}{*}{$F$} \\
\hline & M & SD & M & SD & & \\
\hline Vigilance & .71 & .64 & 1.34 & .88 & .12 & $23.41^{* * *}$ \\
\hline Concealment of mate & .37 & .55 & .42 & .60 & .00 & .19 \\
\hline Monopolization of time & .61 & .63 & .76 & .74 & .01 & 1.84 \\
\hline Jealousy induction & .20 & .44 & .43 & .61 & .03 & $5.78^{* *}$ \\
\hline Punish mate's infidelity threat & .71 & .79 & 1.39 & .96 & .12 & $21.75^{* * *}$ \\
\hline Emotional manipulation & 1.17 & .94 & .96 & .81 & .02 & $3.47^{*}$ \\
\hline Commitment manipulation & 1.37 & .88 & 1.13 & .73 & .02 & $3.45^{*}$ \\
\hline Derogation of competitors & 1.11 & .66 & 1.36 & .77 & .02 & $3.59^{*}$ \\
\hline Resource display & 1.86 & .66 & 1.50 & .71 & .07 & $11.73^{* * *}$ \\
\hline Sexual inducements & 1.64 & .91 & 1.46 & .84 & .01 & 1.52 \\
\hline Appearance enhancement & 2.15 & .67 & 2.49 & .60 & .05 & $8.85^{* *}$ \\
\hline Love and care & 2.76 & .38 & 2.72 & .39 & .00 & .68 \\
\hline Submission and debasement & 1.58 & .65 & 1.46 & .70 & .00 & .89 \\
\hline Verbal possession signals & 1.41 & .85 & 1.48 & .78 & .00 & .02 \\
\hline Physical possession signals & 2.13 & .81 & 2.05 & .85 & .00 & .73 \\
\hline Possessive ornamentation & .79 & .94 & .66 & .87 & .00 & 1.05 \\
\hline Derogation of mate & .22 & .43 & .39 & .59 & .03 & $5.52^{* *}$ \\
\hline Intrasexual threats & 1.10 & .89 & 1.19 & .93 & .00 & .10 \\
\hline Violence against rivals & .04 & .20 & .06 & .33 & .00 & .22 \\
\hline
\end{tabular}

Note. *Marginally significant ( $p \leq .1$, Gelman, 2013); ${ }^{* *} p \leq .05 ;{ }^{* * *} p \leq .001$. probably asked their partner to marry them only one time. Among individuals who are not married, those who never asked their partner to marry them scored "0" (never), which means that the item's variance depends on not-married individuals that ask their partner to marry them several times. The low variance of this item thus explains the low Cronbach's alpha of the Commitment manipulation. Item 26 is also ambiguous regarding the tactics it might represent (i.e. it is not only a commitment manipulation, but might also serve as resource display and as a physical possession signal if there is an engagement ring, in addition to serving as an expression of love and care).

Extraction criteria indicated a two-component structure. Buss (1988) organized the 19 tactics into two domains: intersexual manipulations and intrasexual manipulations. In the current study, the allocation of tactics into components diverged from Buss's categorization in several ways. For instance, resource display and monopolization of time, although directed toward one's partner, loaded onto different components, and jealousy induction and vigilance, which are intersexual and intrasexual manipulations, respectively, demonstrated high loadings on the same component. The two-component structure identified in the present study is similar to the structure suggested by Miner, Starratt, et al. (2009). The allocation of tactics into components (Table 2) shows that Component 1 includes mostly benefit-provisioning tactics, whereas Component 2 includes cost-inflicting tactics. Specifically, Component 1 includes the benefit-provisioning tactics identified by Miner, Starratt, et al. (2009), and also includes three cost-inflicting tactics (emotional manipulation, commitment manipulation, and derogation of competitors). Component 2 includes the cost-inflicting tactics identified by Miner, Starratt, et al. (2009), except for those which saturated in the first component.

Therefore, among the cost-inflicting tactics identified by Miner, Starratt, et al. (2009), three seem to be considered benefit-provisioning by Brazilian participants (emotional manipulation, commitment manipulation, and derogation of competitors). Emotional manipulation and commitment manipulation indicate the participant's interest in a committed relationship, including the items "pleaded that I could not live without my partner" and "told my partner that we needed a total commitment to each other". Such behaviors may be interpreted as benefit-bestowing, in that they demonstrate commitment and devotion to the relationship. Derogation of competitors, although considered costinflicting by Miner, Starratt, et al. (2009), does not clearly inflict direct costs on the partner, but neither does it bestow clear benefits on the partner.

Monopolization of time and intrasexual threats did not load cleanly on either component. These tactics could be interpreted as benefitprovisioning to some respondents. For example, individuals may insist that their partner spend all their free time with them simply because they wish to be with their partner (beneficial) rather than because they intend to retain their partners, e.g. preventing them from meeting new people from their opposite-sex. Similarly, to stare coldly at a samesex person who was looking at their partner can be related to the intention of protecting the partner (beneficial) rather than to an attempt to discourage potential competitors.

We investigated sex differences in the use of mate retention tactics. The results are in line with evolutionarily-informed hypotheses of mate retention (see Introduction). Specifically, men more than women used resource display, and women more than men used appearance enhancement. We expected that men more than women would punish a mate's infidelity threat. Because men face the adaptive problem of paternity uncertainty, men report greater upset than do women in response to a partner's sexual infidelity (Buss, Larsen, Westen, \& Semmelroth, 1992; Carpenter, 2012). On the other hand, because the redirection of a partner's investment to another woman and her offspring is reproductively costly for a woman (Buss et al., 1992), women report greater upset in response to a partner's emotional infidelity (Shackelford, LeBlanc, \& Drass, 2000). However, women may resort to other strategies to obtain resources for them and their offspring, e.g. 
grandmothers may function as alloparents (Sear \& Mace, 2008). Contrary to what we expected, the results indicated that women more than men punish a mate's infidelity threat. Because Brazilian men commit infidelity more than Brazilian women (Abdo, 2004), Brazilian women might be more sensitive to men's behaviors that may suggest infidelity, e.g. they get angry when their partner flirts with other women because this may indicate his intention to be unfaithful.

Previous research indicates that women more than men use jealousy induction to retain their partners (Buss, 1988; Buss \& Shackelford, 1997), and we replicated this finding in the Brazilian context. Furthermore, we found that men report less frequent use of cost-inflicting tactics than do women (Component 2). Cost-inflicting behaviors are more risky than benefit-provisioning behaviors for men to use because although the former behaviors thwart a partner's infidelities (Miner, Starratt, et al., 2009), they also increase the odds of relationship defection (Miner, Shackelford, et al., 2009).

The current study has limitations. Our participants are a nonrandom sample from a single city in Brazil, which restricts the generalizability of the results among Brazilian regions. For instance, Rio de Janeiro has higher infidelity rates than other states (Abdo, 2004), possibly because residents of Rio de Janeiro use mate retention tactics that are less efficient in reducing the likelihood of infidelity compared to residents of other states; and Goiás is among the states with the highest domestic violence rates (Waiselfisz, 2013), suggesting that residents of Goiás use tactics such as vigilance and monopolization of time more frequently than residents of other states.

This study offers several contributions to the mate retention literature. It introduces the MRI-SF for use in the Brazilian context in the form of the ERP-R, a parsimonious measure that can be used in correlational research to investigate evolutionarily-relevant relationship issues. In addition, the ERP-R can be used for the development of predictive models involving important relationship issues in Brazil, such as domestic violence (e.g. by investigating whether use of particular mate retention tactics may portend domestic violence). Finally, the current results provide evidence of similarities and differences in the use of mate retention tactics in different cultural contexts, i.e. North America and Brazil. The evolutionary psychological hypotheses of mate selection and mate retention have been subjected to intense empirical scrutiny in North America and Western Europe. We recommend this research be extended to include assessments of Brazilians and other South American participants.

\section{Appendix A. Supplementary data}

Supplementary data to this article can be found online at http://dx. doi.org/10.1016/j.paid.2015.10.033.

\section{References}

Abdo, C. H. N. (2004). Descobrimento sexual do Brasil: para curiosos e estudiosos [Sexual discovery of Brazil: for curious and scholars]. São Paulo: Summus.

Borsa, J.C., Damásio, B.F., \& Bandeira, D.R. (2012). Adaptação e validação de instrumentos psicológicos entre culturas: algumas considerações [Cross-cultural adaptation and validation of psychological instruments: Some considerations]. Paidéia (Ribeirão Preto), 22(53), 423-432.

Buss, D.M. (1988). From vigilance to violence: Tactics of mate retention in American undergraduates. Ethol. Sociobiol., 9(5), 291-317.

Buss, D.M. (2003). The evolution of desire: Strategies of human mating. New York, NY: Basic Books.

Buss, D.M., \& Shackelford, T.K. (1997). From vigilance to violence: Mate retention tactics in married couples. J. Pers. Soc. Psychol., 72(2), 346.

Buss, D.M., Larsen, R.J., Westen, D., \& Semmelroth, J. (1992). Sex differences in jealousy: Evolution, physiology, and psychology. Psychol. Sci., 3(4), 251-255.

Buss, D.M., Shackelford, T.K., \& McKibbin, W.F. (2008). The mate retention inventory Short form (MRI-SF). Personal. Individ. Differ., 44, 322-334.

Carpenter, C.J. (2012). Meta-analyses of sex differences in responses to sexual versus emotional infidelity men and women are more similar than different. Psychol. Women Q., 36(1), 25-37.

Eisinga, R., TeGrotenhuis, M., \& Pelzer, B. (2013). The reliability of a two-item scale: Pearson, Cronbach, or Spearman-Brown? International Journal of Public Health, 58(4), 637-642.

Gallup, G.G., Jr., \& Frederick, D.A. (2010). The science of sex appeal: An evolutionary perspective. Rev. Gen. Psychol., 14(3), 240

Garrido, L.E., Abad, F.J., \& Ponsoda, V. (2013). A new look at Horn's parallel analysis with ordinal variables. Psychol. Methods, 18(4), 454

Geldart, S. (2010). That woman looks pretty, but is she attractive? Female perceptions of facial beauty and the impact of cultural labels. Revue Européenne de Psychologie Appliquée/European Review of Applied Psychology, 60(2), 79-87.

Gelman, A. (2013). P values and statistical practice. Epidemiology, 24(1), 69-72.

Horn, J.L. (1965). A rationale and test for the number of factors in factor analysis Psychometrika, 30, 179-185.

Kaiser, H.F. (1970). A second generation little jiffy. Psychometrika, 35, 401-416.

Kardum, I., Hudek-Knezevic, J., \& Gracanin, A. (2006). Sociosexuality and mate retention in romantic couples. Psihologijske Teme, 5, 277-296.

Kline, P. (1979). Psychometrics and psychology. London, UK: Academic Press.

de Miguel, A., \& Buss, D.M. (2011). Mate retention tactics in Spain: Personality, sex differences, and relationship status. J. Pers., 79(3), 563-586.

Miner, E.J., Shackelford, T.K., \& Starratt, V.G. (2009). Mate value of romantic partners predicts men's partner-directed verbal insults. Personal. Individ. Differ., 46, 135-139.

Miner, E.J., Starratt, V.G., \& Shackelford, T.K. (2009). It's not all about her: Men's mate value and mate retention. Personal. Individ. Differ., 47(3), 214-218.

Nunnally, J.C. (1970). Introduction to psychological measurement. New York: McGraw-Hill.

Pham, M.N., \& Shackelford, T.K. (2013). Oral sex as mate retention behavior. Personal. Individ. Differ., 55(2), 185-188.

Pham, M.N., Barbaro, N., Mogilski, J.K., \& Shackelford, T.K. (2015). Coalitional mate retention is correlated positively with friendship quality involving women, but negatively with male-male friendship quality. Personal. Individ. Differ., 79, 87-90.

Sear, R., \& Mace, R. (2008). Who keeps children alive? A review of the effects of kin on child survival. Evol. Hum. Behav., 29, 1-18.

Shackelford, T.K., Goetz, A.T., \& Buss, D.M. (2005). Mate retention in marriage: Further evidence of the reliability of the mate retention inventory. Personal. Individ. Differ., 39(2), 415-425.

Shackelford, T.K., Goetz, A.T., Buss, D.M., Euler, H.A., \& Hoier, S. (2005). When we hurt the ones we love: Predicting violence against women from men's mate retention. Pers. Relat., 12(4), 447-463.

Shackelford, T.K., LeBlanc, G.J., \& Drass, E. (2000). Emotional reactions to infidelity. Cognition \& Emotion, 14(5), 643-659.

Waiselfisz, J.J. (2013). Mapa da violência 2013: Homicídios e juventude no Brasil [Map of the violence 2013: Homicides and youth in Brazill. Brasília, DF: Secretaria-Geral da Presidência da República (Retrieved from: http://www.mapadaviolencia.org.br/ pdf2013/mapa2013_homicidios_juventude.pdf). 